\title{
Dietary oxidised fat up regulates the expression of organic cation transporters in liver and small intestine and alters carnitine concentrations in liver, muscle and plasma of rats
}

\author{
Alexander Koch, Bettina König, Sebastian Luci, Gabriele I. Stangl and Klaus Eder* \\ Institute of Agricultural and Nutritional Sciences, Martin-Luther-University of Halle-Wittenberg, Emil-Abderhalden-Strasse 26, \\ D-06108 Halle (Saale), Germany
}

(Received 19 December 2006 - Revised 3 April 2007 - Accepted 12 April 2007)

It has been shown that treatment of rats with clofibrate, a synthetic agonist of PPAR $\alpha$, increases mRNA concentration of organic cation transporters (OCTN)-1 and -2 and concentration of carnitine in the liver. Since oxidised fats have been demonstrated in rats to activate hepatic PPAR $\alpha$, we tested the hypothesis that they also up regulate OCTN. Eighteen rats were orally administered either sunflower-seed oil (control group) or an oxidised fat prepared by heating sunflower-seed oil, for $6 \mathrm{~d}$. Rats administered the oxidised fat had higher mRNA concentrations of typical PPAR $\alpha$ target genes such as acyl-CoA oxidase, cytochrome P450 4A1 and carnitine palmitoyltransferases-1A and -2 in liver and small intestine than control rats $(P<0 \cdot 05)$. Furthermore, rats treated with oxidised fat had higher hepatic mRNA concentrations of OCTN1 (1.5-fold) and OCTN2 (3.1fold), a higher carnitine concentration in the liver and lower carnitine concentrations in plasma, gastrocnemius and heart muscle than control rats $(P<0 \cdot 05)$. Moreover, rats administered oxidised fat had a higher mRNA concentration of OCTN2 in small intestine $(2 \cdot 4$-fold; $P<0.05)$ than control rats. In conclusion, the present study shows that an oxidised fat causes an up regulation of OCTN in the liver and small intestine. An increased hepatic carnitine concentration in rats treated with the oxidised fat is probably at least in part due to an increased uptake of carnitine into the liver which in turn leads to reduced plasma and muscle carnitine concentrations. The present study supports the hypothesis that nutrients acting as PPAR $\alpha$ agonists influence whole-body carnitine homeostasis.

Carnitine: Oxidised fat: Peroxisome proliferator-activated receptor- $\alpha$ : Organic cation transporters

Carnitine (L-3-hydroxy-4-N-N-N-trimethylaminobutyrate) is an essential metabolite that has a number of indispensable functions in intermediary metabolism. The most prominent function lies in its role in the transport of activated longchain fatty acids from the cytosol to the mitochondrial matrix where $\beta$-oxidation takes place ${ }^{1-3}$. All tissues that use fatty acids as a fuel source require carnitine for normal function. Carnitine is derived from dietary sources and endogenous biosynthesis ${ }^{4}$. Carnitine biosynthesis involves a complex series of reactions involving several tissues ${ }^{5}$. Lysine provides the carbon backbone of carnitine. Lysine in protein peptide linkages undergoes methylation of the $\epsilon$-amino group to yield trimethyllysine, which is released upon protein degradation. Muscle is the major source of trimethyllysine. The released trimethyllysine is further oxidised to butyrobetaine by the action of trimethyllysine dioxygenase, 3-hydroxy- $\mathrm{N}$-trimethyllysine aldolase and 4- $N$-trimethylaminobutyraldehyde dehydrogenase. Butyrobetaine is hydroxylated by $\gamma$-butyrobetaine dioxygenase to form carnitine. The last reaction which is rate-limiting for carnitine synthesis occurs primarily in the liver and kidneys ${ }^{6}$ (see Fig. 1).

Distribution of carnitine within the body and intracellular homeostasis of carnitine are controlled by organic cation transporters (OCTN) which belong to the solute carrier (SLC) $22 \mathrm{~A}$ family, localised to the apical membrane of cells ${ }^{7,8}$. Three OCTN have been identified so far: OCTN1, OCTN2 and OCTN $3^{9-11}$. OCTN are polyspecific; they transport several cations and L-carnitine ${ }^{12,13}$. Carnitine transport by OCTN1 and OCTN2 is Na dependent whereas that by OCTN3 is Na independent ${ }^{11}$. OCTN1 and OCTN2 are expressed in several tissues such as kidney, intestine, skeletal muscle, heart, liver and brain ${ }^{11,14,15}$. In contrast, OCTN3 is expressed exclusively in the testes and kidneys ${ }^{11}$. Among the three OCTN, OCTN3 has the highest specificity for carnitine; OCTN1 has the lowest one ${ }^{11}$. OCTN operate on the intestinal absorption and renal reabsorption of carnitine and play a major role in tissue distribution by catalysing the uptake of carnitine into body cells. Due to its high binding affinity for carnitine and its wide expression, OCTN2 seems to be the most physiologically important carnitine transporter. OCTN1 contributes less to carnitine transport than OCTN2 due to its low carnitine transport activity. OCTN3 may be important for carnitine uptake into the testes, and may contribute to the reabsorption of carnitine in the kidneys ${ }^{11}$. The fact that inborn or acquired defects of OCTN lead to primary or secondary systemic carnitine deficiency demonstrates their essential role in carnitine homeostasis ${ }^{8}$. 
TML

(From protein degradation)

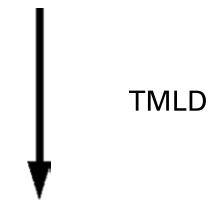

HTML

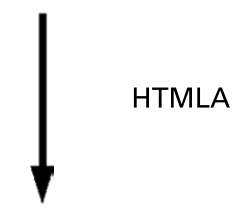

TMABA

Fig. 1. Schematic diagram of carnitine biosynthesis from trimethyllysine (TML) (according to $\mathrm{Vaz} \&$ Wanders $^{6}$ ). TML is oxidised to butyrobetaine by trimethyllysine dioxygenase (TMLD), 3-hydroxy- $N$-trimethyllysine aldolase (HTMLA) and 4- $\mathrm{N}$-trimethylaminobutyraldehyde dehydrogenase (TMABA-DH). In the last rate-limiting step, butyrobetaine is hydroxylated to L-carnitine by $\gamma$-butyrobetaine dioxygenase (BBD). HTML, 3-hydroxy- $N$-trimethyllysine; TMABA, 4- $N$-trimethylaminobutyraldehyde.

It has been shown previously that starvation or treatment of rats with clofibrate increases the concentration of carnitine in the liver ${ }^{16-18}$. Both starvation and clofibrate treatment lead to an activation of PPAR $\alpha$, a transcription factor belonging to the nuclear hormone receptor superfamily ${ }^{19}$. We have recently shown that activation of PPAR $\alpha$ by clofibrate treatment causes an up regulation of OCTN1 and OCTN2 in rat liver $^{20}$. These results strongly indicated that increased carnitine concentrations in livers of rats starved or treated with clofibrate were due to increased uptake of carnitine from blood into the liver. Indeed, plasma carnitine concentrations were reduced in rats treated with clofibrate which may be caused by an increased uptake into the liver ${ }^{20}$.

In addition to synthetic agonists, several naturally occurring compounds are able to activate PPAR $\alpha$ in vivo. Recently, we and others have shown that dietary oxidised fats prepared by the heating of vegetable oils activate hepatic PPAR $\alpha$ in rats and pigs $^{21-25}$. In the present study, we tested the hypothesis that oxidised fats are also able to up regulate the expression of OCTN (OCTN1, OCTN2) in the liver due to their ability to activate $\operatorname{PPAR} \alpha$ and thereby increase hepatic carnitine concentration. For this end, we performed an experiment with growing rats as an animal model, according to a previous study dealing with the effects of an oxidised oil on PPAR $\alpha$ activation $^{24}$.

More than $95 \%$ of the total carnitine in the body is localised in the muscle which serves as a carnitine storage ${ }^{2}$. When plasma carnitine concentrations are lowered, such as by treatment with pivalate, carnitine is mobilised from the muscle in order to normalise plasma carnitine concentrations ${ }^{26}$. Therefore, an increased uptake of carnitine from the blood into the liver by up regulation of hepatic OCTN should lead to a mobilisation of carnitine storage in the muscle. To investigate this, we also determined carnitine concentrations in skeletal muscle and heart of the rats.

OCTN1 and OCTN2 are also highly expressed in the intestine and particularly OCTN2 plays an important role in the absorption of L-carnitine from the $\operatorname{diet}^{15,27,28}$. As the small intestine also has a high expression of PPAR $\alpha$, it seems possible that an oxidised fat could increase the gene expression of OCTN also in the small intestine via an activation of PPAR $\alpha$. Besides OCTN, the amino acid transporter $\mathrm{ATB}^{0+}$ is involved in the intestinal absorption of carnitine from the diet ${ }^{27,29}$. In order to obtain information whether PPAR $\alpha$ activation by synthetic or native agonists could influence intestinal carnitine absorption, we also determined mRNA concentration of $\mathrm{ATB}^{0+}$ in small intestine.

\section{Materials and methods}

\section{Animal experiment}

Male Sprague-Dawley rats, aged 5 weeks old, supplied by Charles River (Sulzfeld, Germany) with an average initial body weight of 115 (SD 14) g were randomly assigned to two groups of nine rats each. They were kept individually in Macrolon cages in a room controlled for temperature $\left(22 \pm 2^{\circ} \mathrm{C}\right)$, relative humidity $(50-60 \%)$ and light $(12 \mathrm{~h}$ light-dark cycle). All experimental procedures described followed established guidelines for the care and handling of laboratory animals and were approved by the council of Saxony-Anhalt. The animals received either $2 \mathrm{ml}$ fresh sunflower-seed oil (control group) or oxidised sunflower-seed oil (see Preparation of the oxidised fat) by oral administration once per $\mathrm{d} 2 \mathrm{~h}$ after the beginning of the light cycle. Afterwards, they obtained their daily food ration. All rats were fed a commercial standard basal diet (Altromin 1324; Altromin GmbH, Lage, Germany). Concentration of total carnitine in the basal diet was $22 \mu \mathrm{mol} / \mathrm{kg}$. To standardise food intake, diet intake was controlled. Each rat in the experiment received $12 \mathrm{~g} \mathrm{diet} / \mathrm{d}$. This amount of diet which is approximately $20 \%$ below the amount of diet rats would consume ad libitum was completely ingested by all rats. Thus, the diet intake was identical in all the rats within this experiment. Water was available ad libitum from nipple drinkers during the whole experiment. At day 6 of treatment, rats received the last dose of fresh or oxidised fat and $9 \mathrm{~g}$ diet and were killed $4 \mathrm{~h}$ later by decapitation under light anaesthesia with diethyl ether. Blood was collected into heparinised polyethylene tubes. Liver, heart 
and gastrocnemius muscles were quickly removed, frozen with liquid $\mathrm{N}_{2}$ and stored at $-80^{\circ} \mathrm{C}$ pending further analysis. Plasma was obtained by centrifugation of the blood $(1100 \mathrm{~g}$; $10 \mathrm{~min} ; 4^{\circ} \mathrm{C}$ ) and stored at $-20^{\circ} \mathrm{C}$. Liver samples for RNA isolation and lipid extraction were snap-frozen in liquid $\mathrm{N}_{2}$ and stored at $-80^{\circ} \mathrm{C}$. The small intestine was rapidly excised, washed with cold $0.9 \% \mathrm{NaCl}(\mathrm{w} / \mathrm{v})$ and mucosal scrapings were obtained from the jejunum (defined by length), snapfrozen and stored at $-80^{\circ} \mathrm{C}$ for RNA extraction.

\section{Preparation of the oxidised fat}

The thermoxidised oil was prepared by heating sunflower-seed oil obtained from a local supermarket in an electric fryer (Saro Gastro-Products $\mathrm{GmbH}$, Emmerich, Germany) for $25 \mathrm{~d}$ at $60^{\circ} \mathrm{C}$. Throughout the heating process, air was continuously bubbled into the fat. The extent of lipid peroxidation was determined by assaying the peroxide value ${ }^{30}$, concentration of thiobarbituric acid-reactive substances ${ }^{31}$ and conjugated dienes ${ }^{32}$, acid values ${ }^{30}$, the percentage of total polar compounds ${ }^{33}$ and the concentration of total carbonyls ${ }^{34}$. The oxidised fat had much higher concentrations of peroxides (126-fold), conjugated dienes $(>2740$-fold), thiobarbituric acid-reactive substances (12-fold), total carbonyls (33-fold), polar compounds (5-fold) and a higher acid value (15-fold) than the fresh fat (Table 1).

\section{Carnitine analysis}

Carnitine was determined as $\left[{ }^{3} \mathrm{H}\right]$ acetyl-carnitine after the esterification of non-esterified carnitine by carnitine acyltransferase according to McGarry \& Foster ${ }^{35}$ with modifications proposed by Parvin \& Pande ${ }^{36}$ and Christiansen \& Bremer ${ }^{37}$. Plasma samples were used directly for the determination of the total carnitine after alkaline hydrolysation as described for the tissue samples below. Tissue samples were freeze dried and milled. Then $100 \mathrm{mg}$ liver or $50 \mathrm{mg}$ muscle powder were sonificated in $5 \mathrm{ml}$ water for $15 \mathrm{~min}$. Samples were centrifuged (12000 g; $5 \mathrm{~min}$ ) and non-esterified carnitine in the supernatant fraction was measured. For the determination of the total carnitine the samples were hydrolysed before the centrifugation. For this, $10 \mathrm{ml} 0 \cdot 2 \mathrm{M}$-potassium hydroxide were added, the samples were incubated at $30^{\circ} \mathrm{C}$ for $1 \mathrm{~h}$ and then neutralised by the addition of $0.2 \mathrm{M}-\mathrm{HCl}$. Carnitine esterification was done in a final volume of $1 \mathrm{ml}$ containing $0 \cdot 1 \mathrm{M}-\mathrm{HEPES}(\mathrm{pH} 7 \cdot 4), 2 \mathrm{mM}-$ $N$-ethylmaleimide, $\quad 1.25 \mathrm{~mm}$-EDTA, $25 \mu \mathrm{M}-\left[{ }^{3} \mathrm{H}\right]$ acetyl-CoA (29.4 MBq/mmol; GE Healthcare, Buckinghamshire, UK) and $1 \mathrm{U}$ carnitine acyltransferase (Roche Diagnostic, Mannheim, Germany) for $30 \mathrm{~min}$ at room temperature. $\left[{ }^{3} \mathrm{H}\right]$ acetyl-CoA not

Table 1. Concentrations of various lipid oxidation products in the fats ${ }^{\star}$

\begin{tabular}{lcc}
\hline Oxidation product & Fresh fat & Oxidised fat \\
\hline Peroxide value $\left(\mathrm{mEq} \mathrm{O}_{2} / \mathrm{kg}\right)$ & 3.0 & 378.6 \\
Conjugated dienes $(\mathrm{mmol} / \mathrm{kg})$ & $<0.1$ & 273.6 \\
TBARS $(\mathrm{mmol} / \mathrm{kg})$ & 1.1 & 13.1 \\
Total carbonyls $(\mathrm{mmol} / \mathrm{kg})$ & 2.9 & 96.9 \\
Total polar compounds $(\%)$ & $5 \cdot 1$ & 27.8 \\
Acid value $(\mathrm{g} \mathrm{KOH} / \mathrm{kg})$ & 0.4 & 5.8 \\
\hline
\end{tabular}

TBARS, thiobarbituric acid-reactive substances.

*Data are the results of single measurements. consumed by the reaction was bound to Dowex 1-X 8 and separated by centrifugation. Carnitine concentration was calculated using the radioactivity of the supernatant fraction measured in a liquid scintillation counter and corrected for non-specific radioactivity.

\section{Reverse transcriptase polymerase chain reaction analysis}

Total RNA was isolated from rat livers and mucosa scrapings, respectively, by TRIZOL ${ }^{\mathrm{TM}}$ reagent (Sigma-Aldrich, Steinheim, Germany) according to the manufacturer's protocol. cDNA synthesis was carried out as described ${ }^{38}$. The mRNA concentration of genes was measured by real-time detection PCR using SYBR $^{\circledR}$ Green I and the Rotor Gene 2000 system (Corbett Research, Mortlake, Australia). Real-time detection PCR was performed with 1.25 U Taq DNA polymerase (Promega, Mannheim, Germany), $500 \mu \mathrm{M}-\mathrm{dNTP}$ and $26.7 \mathrm{pmol}$ of the specific primers (Operon Biotechnologies, Cologne, Germany; Table 2). Annealing temperature for all primers was $60^{\circ} \mathrm{C}$. For determination of mRNA concentration a threshold cycle $\left(\mathrm{C}_{\mathrm{t}}\right)$ and amplification efficiency was obtained from each amplification curve using the software RotorGene 4.6 (Corbett Research). Calculation of the relative mRNA concentration was made using the $\Delta \Delta \mathrm{C}_{\mathrm{t}}$ method as previously described ${ }^{39}$. The housekeeping gene glyceraldehyde-3-phosphate dehydrogenase was used for normalisation. mRNA concentration of glyceraldehyde-3-phosphate dehydrogenase was not influenced by the treatment of rats with oxidised fat.

\section{Statistical analysis}

Means of the treatment and control groups were compared by an unpaired $t$ test using the Minitab Statistical Software (Minitab, State College, PA, USA). Differences with $P<0.05$ were considered to be significant.

\section{Results}

Final weights and body-weight gains of the rats

Final body weights of rats treated with the oxidised fat (133 (SD 14) g) were not significantly different from the control rats (144 (SD 14) g) (nine rats for each group). However, rats treated with the oxidised fat had a lower body-weight gain (17.5 (SD 6.4) g) over the feeding period than the control rats $(29.7(\mathrm{SD} 4 \cdot 5) \mathrm{g})$ (nine rats for each group; $P<0.05)$.

mRNA concentrations of acyl-CoA oxidase, cytochrome P450$4 A 1$, carnitine palmitoyltransferases- $1 A$ and -2 , organic cation transporters- 1 and -2 and enzymes involved in hepatic carnitine synthesis (trimethyllysine dioxygenase, 4- $\mathrm{N}$ trimethylaminobutyraldehyde dehydrogenase and $\gamma$-butyrobetaine dioxygenase) in the liver

Rats treated with the oxidised fat had higher mRNA concentrations of acyl-CoA oxidase, cytochrome P450 (Cyp)-4A1, carnitine palmitoyltransferase (CPT)-2, OCTN1 and OCTN2 in the liver than control rats $(P<0.05)$; mRNA concentration of CPT1A, however, was not different in the rats treated with oxidised fat from the control rats (Fig. 2). Rats treated with the oxidised fat had a higher mRNA concentration of trimethyllysine dioxygenase in the liver than control 
Table 2. Characteristics of the primers used in reverse transcriptase polymerase chain reaction analysis

\begin{tabular}{lllll}
\hline Gene & Forward primer (from 5' to $3^{\prime}$ ) & Reverse primer (from 5' to $3^{\prime}$ ) & bp & NCBI GenBank \\
\hline ACO & CTTTCTTGCTTGCCTTCCTTCTCC & GCCGTTTCACCGCCTCGTA & 415 & NM_017340 \\
ATB $^{0+}$ & ATCCGGAAGACTAGCTCAA & CCCAGTAAATTCCAGCCTGA & 237 & NM_001037544 \\
BBD & ATTCTGCAAAAGCTCGGAAA & CTCCTTGGAGTCCTGCTCTG & 183 & NM_022629 \\
Cyp4A1 & CAGAATGGAGAATGGGGACAGC & TGAGAAGGGCAGGAATGAGTGG & 460 & NM_175837 \\
CPT1A & GGAGACAGACACCATCCAACATA & AGGTGATGGACTTGTCAAACC & 416 & NM_031559 \\
CPT2 & TCCTCGATCAAGATGGGAAC & GATCCTTCATCGGGAAGTCA & 237 & NM_012930 \\
GAPDH & GCATGGCCTTCCGTGTTCC & GGGTGGTCCAGGGTTTCTTACTC & 337 & BC059110 \\
OCTN1 & AGCATTTGTCCTGGGAACAG & ACTCAGGGATGAACCACCAG & 200 & NM_022270 \\
OCTN2 & CCTCTCTGGCCTGATTGAAG & CTCCGCTGTGAAGACGTACA & 226 & NM_012930 \\
TMLD & GCCCTGTGGCATTCAAGTAT & GGTCCAACCCCTATCATGTG & 201 & AF374406 \\
TMABA-DH & TTTGAGACTGAAGCCGAGGT & CACCGGGCTGACGTTATAGT & 156 & NM_022273
\end{tabular}

ACO, acyl-CoA oxidase; BBD, $\gamma$-butyrobetaine dioxygenase; Cyp, cytochrome P450; CPT, carnitine palmitoyltransferase; GAPDH, glyceraldehyde-3-phosphate dehydrogenase; OCTN, organic cation transporter; TMLD, trimethyllysine dioxygenase; TMABA-DH, 4- $N$-trimethylaminobutyraldehyde dehydrogenase.

rats $(P<0.05$; Fig. 2). mRNA concentrations of $4-N$-trimethylaminobutyraldehyde dehydrogenase and $\gamma$-butyrobetaine dioxygenase in the liver, however, did not differ between the two groups of rats (Fig. 2).

mRNA concentrations of acyl-CoA oxidase, cytochrome P450$4 A 1$, carnitine palmitoyltransferases- $1 A$ and -2 , organic cation transporters- 1 and -2 and $A T B^{O+}$ in the small intestine

Rats treated with oxidised fat had higher mRNA concentrations of acyl-CoA oxidase, Cyp4A1, CPT1A, CPT2 and OCTN2 $(P<0.05)$, and they tended to have a higher mRNA concentration of OCTN1 $(P=0.066)$ in the small intestine compared with control rats (Fig. 3). mRNA concentration of $\mathrm{ATB}^{0+}$ in the small intestine was reduced in the rats fed the oxidised fat compared with those fed the fresh fat $(P<0 \cdot 05$; Fig. 3).

\section{Carnitine concentrations in liver, plasma and muscle}

Rats treated with the oxidised fat had a higher carnitine concentration in the liver than control rats $(P<0 \cdot 05$, Fig. 4).

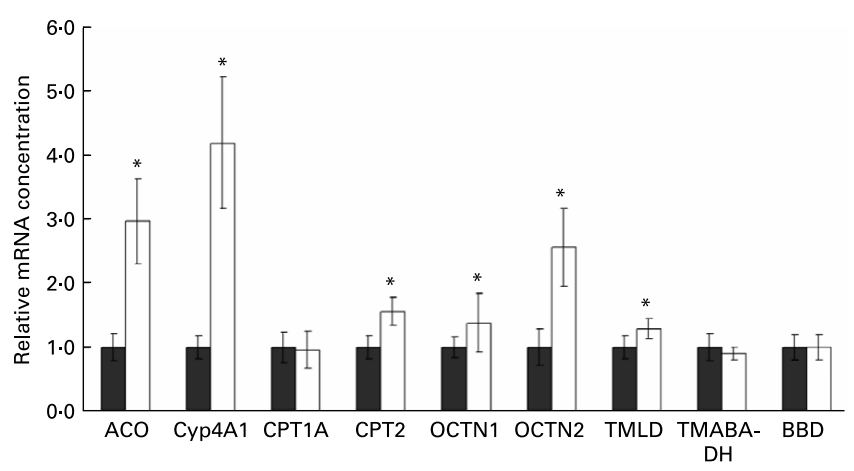

Fig. 2. Effect of an oxidised fat on the relative mRNA concentrations of acyl-CoA oxidase (ACO), cytochrome P450 (Cyp)-4A1, carnitine palmitoyltransferases (CPT)-1A and -2 , organic cation transporters (OCTN)-1 and -2 , trimethyllysine dioxygenase (TMLD), 4- $N$-trimethylaminobutyraldehyde dehydrogenase (TMABA-DH) and $\gamma$-butyrobetaine dioxygenase (BBD) in the liver of rats. Rats were treated orally with $2 \mathrm{ml}$ oxidised fat $(\square)$ or fresh fat ( control $=1.00$ ) for $6 \mathrm{~d}$. Total RNA was extracted from rat livers and mRNA concentrations were determined by real-time detection RT-PCR analysis using glyceraldehyde-3-phosphate dehydrogenase mRNA concentration for normalisation. Values are means, with standard deviations represented by vertical bars ( $n$ 9). *Mean value was significantly different from that of the control rats $(P<0.05)$.
Plasma carnitine concentration was lower in the rats treated with oxidised fat $(18.8(\mathrm{SD} \mathrm{3.1)} \mu \mathrm{mol} / \mathrm{l})$ than in the control group (28.4 (SD 4.3) $\mu \mathrm{mol} / \mathrm{l}$ ) (nine rats for each group; $P<0 \cdot 05)$. Rats treated with oxidised fat also had lower carnitine concentrations in gastrocnemius and heart muscle than control rats $(P<0 \cdot 05$; Fig. 4$)$.

\section{Discussion}

We have recently found that treatment with clofibrate causes a strong up regulation of OCTN2, and a less strong up regulation of OCTN1, in the liver of rats which was accompanied by an increased hepatic carnitine concentration ${ }^{20}$. This effect was probably caused by $\operatorname{PPAR} \alpha$ activation. In the present study, we investigated the hypothesis that oxidised fats are able to exert similar effects due to their ability to activate PPAR $\alpha$. Hydroxy- and hydroperoxy fatty acids such as hydroxyoctadecadienoic and hydroperoxyoctadecadienoic acid occurring in oxidised fats are very potent PPAR $\alpha$ agonists $^{38,40,41}$. These fatty acids are produced during the early stage of lipid peroxidation. Since they are unstable and decompose at high temperatures, fats treated at low temperature have much higher concentrations of these primary lipid

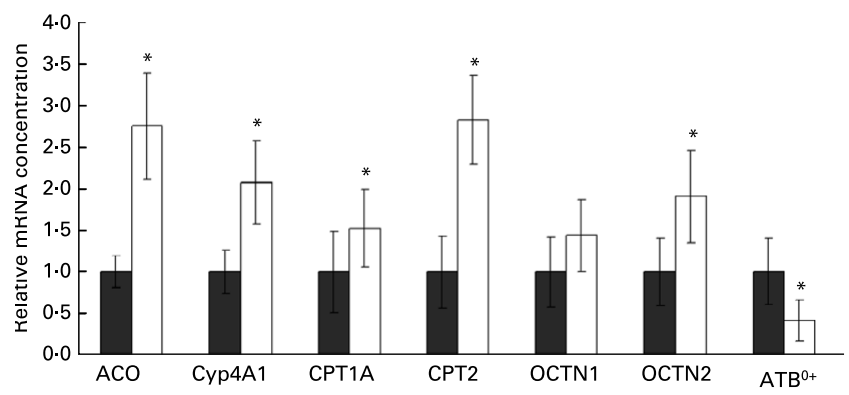

Fig. 3. Effect of an oxidised fat on the relative mRNA concentrations of acylCoA oxidase (ACO), cytochrome P450 (Cyp)-4A1, carnitine palmitoyltransferases (CPT)-1A and -2 , organic cation transporters (OCTN)-1 and -2 and amino acid transporter $\mathrm{ATB}^{0+}$ in the small intestine of rats. Rats were treated orally with $2 \mathrm{ml}$ oxidised fat $(\square)$ or fresh fat $(\square$; control $=1.00)$ for $6 \mathrm{~d}$. Total RNA was extracted from mucosal scrapings and mRNA concentrations were determined by real-time detection RT-PCR analysis using glyceraldehyde-3phosphate dehydrogenase mRNA concentration for normalisation. Values are means, with standard deviations represented by vertical bars ( $n 9)$. *Mean value was significantly different from that of the control rats $(P<0.05)$. 


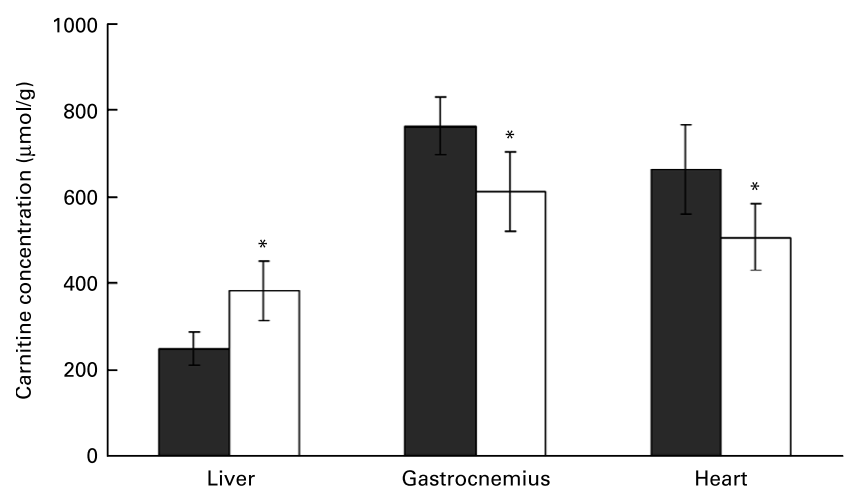

Fig. 4. Effect of an oxidised fat on the concentrations of total carnitine in liver, gastrocnemius and heart. Rats were treated orally with $2 \mathrm{ml}$ oxidised fat $(\square)$ or fresh fat $(\boldsymbol{\square}$; control) for $6 \mathrm{~d}$. Values are means, with standard deviations represented by vertical bars $(n 9)$. *Mean value was significantly different from that of the control rats $(P<0.05)$.

peroxidation products than fats treated at high temperature ${ }^{24}$. This is the reason why we used a fat treated at a relatively low temperature for a long period. The high peroxide value and the high concentration of conjugated dienes indicate that this fat indeed had high concentrations of hydroxy- and hydroperoxy fatty acids which may be particularly responsible for the PPAR $\alpha$-activating effects of oxidised fats. To ensure that all rats obtained the same dose of oxidised fat, it was administered orally. The oxidised and fresh fat, respectively, accounted for about $25 \%$ of total energy of the total daily feed. Since it was observed in a previous rat study that even short-term application of a PPAR $\alpha$ agonist led to the typical changes known for PPAR $\alpha$ activation such as up regulation of classical target genes involved in $\beta$-oxidation and reduction of TAG concentration ${ }^{38}$, we decided to give the oxidised fat over a relatively short time of $6 \mathrm{~d}$. It has been shown that the intake of oxidised fats could cause a reduction of the food intake in rats which could cause secondary effects which interact with the effect of treatment ${ }^{42,43}$. To ensure an identical food intake in both groups of rats, we used a controlled feeding system in which each rat consumed $12 \mathrm{~g}$ $\operatorname{diet} / \mathrm{d}$. This amount of diet is slightly below that that rats would consume ad libitum but in clear excess of that necessary to meet the maintenance energy requirement (which is approximately $6 \mathrm{~g} / \mathrm{d}^{44}$ ) and ensures an adequate growth of the rats. It is known that fasting causes an activation of PPAR $\alpha$ due to the release of NEFA from the adipose tissue $^{45}$. To avoid PPAR $\alpha$ activation due to an insufficient supply of energy, all the rats received their last portion of diet $4 \mathrm{~h}$ before decapitation. Therefore, we can exclude the possibility that PPAR $\alpha$ was also activated in the control group fed the fresh fat. The finding that rats fed the oxidised fat gained less weight during the experimental period than those fed the fresh fat although both groups received an identical amount of diet indicates that the oxidised fat impaired the feed conversion ratio. This finding agrees with other reports which also showed that feeding of oxidised fats impairs the growth of rats ${ }^{46-49}$. We did not investigate the reason for this. Previous studies, however, have shown that oxidised fats lower the digestibility of nutrients ${ }^{46,50}$ and this may be the reason for the reduced body-weight gains of the rats fed the oxidised fat observed in the present study. However, as rats fed the oxidised fat appeared quite normal, we assume that the oxidised fat did not cause general toxicity.

The finding of increased mRNA concentrations of the typical PPAR $\alpha$ downstream genes acyl-CoA oxidase, Cyp4A1, CPT1A and CPT2 (for a review, see Mandard et $a l^{45}$ ) in liver and intestine indeed indicates that the oxidised fat caused an activation of PPAR $\alpha$ in both liver and intestine of the rats. This indication agrees with recent studies in rats and pigs which also showed that intake of oxidised fats leads to an activation of PPAR $\alpha$ in the liver ${ }^{21-25}$.

The present study shows further that treatment of rats with an oxidised fat caused the same alterations as observed for clofibrate $^{20}$, namely increased hepatic mRNA concentrations of OCTN1 and OCTN2 and an increased hepatic carnitine concentration. Considering that a similar up regulation of OCTN1 and OCTN2 was observed in the liver of rats treated with the synthetic PPAR $\alpha$ agonist clofibrate and in rat hepatoma cells treated with the more potent and selective PPAR $\alpha$ agonist WY $14,643^{20}$, we propose that the oxidised fat up regulated OCTN in the liver also by PPAR $\alpha$ activation.

In rat liver, OCTN1 and OCTN2 are highly expressed ${ }^{15}$. Both of them are able to transport carnitine into the liver cell $^{51,52}$. However, it has been shown that OCTN2 has a higher carnitine transport activity than OCTN $1^{11}$. For that reason and as mRNA concentration of OCTN2 was more strongly increased by the oxidised fat than that of OCTN1, we assume that increased hepatic carnitine concentrations in rats treated with oxidised fat were caused mainly by an increased uptake of carnitine via OCTN2. Plasma carnitine concentrations are regulated by several events, namely intestinal absorption from the diet, renal excretion, endogenous synthesis in the liver and kidneys and movement of carnitine between plasma and tissues ${ }^{53}$. We have not studied the pharmacokinetics of carnitine but it seems plausible that reduced plasma concentrations of carnitine in rats fed the oxidised fat may at least in part be due to an enhanced uptake into the liver. We measured mRNA concentrations of OCTN only in liver and small intestine; however, it is possible that they were increased also in other tissues in rats fed the oxidised fat. Therefore, an increased uptake of carnitine into other tissues besides liver could also contribute to the reduced plasma carnitine concentrations. In the kidney, OCTN2 functions to reabsorb carnitine from the urine ${ }^{13,54}$. An up regulation of OCTN2 in kidney would be expected to reduce urinary excretion of carnitine which in turn results in an increased plasma carnitine concentration. However, the effect of oxidised fats on the gene expression of OCTN in those tissues and their consequences on whole-body carnitine homeostasis should be determined in future studies.

In the present study we also determined mRNA concentrations of various enzymes involved in hepatic carnitine biosynthesis in the liver which belongs like the kidney to the tissues being able to synthesise carnitine ${ }^{6}$. It was found that oxidised fat treatment led to a moderate up regulation of trimethyllysine dioxygenase while mRNA concentrations of 4- $\mathrm{N}$-trimethylaminobutyraldehyde dehydrogenase and $\gamma$-butyrobetaine dioxygenase, the rate-limiting enzyme of carnitine biosynthesis ${ }^{6}$, remained unchanged by the treatment. This finding shows that PPAR $\alpha$ activation by the oxidised oil does not up regulate the gene expression of enzymes involved in hepatic carnitine synthesis. Nevertheless, it is 
possible that carnitine hepatic biosynthesis was increased in rats treated with oxidised fat. The liver has a high capacity to convert $\gamma$-butyrobetaine into carnitine ${ }^{6}$. As OCTN2 has a high affinity for $\gamma$-butyrobetaine ${ }^{10,11}$ it is likely that an increased expression of OCTN2 may have led to an increased uptake of $\gamma$-butyrobetaine from plasma into the liver which in term may have stimulated synthesis of carnitine in the liver. This assumption, however, has to be proven in further studies.

Muscle contains more than $95 \%$ of whole-body carnitine and serves as a carnitine storage ${ }^{2}$. When plasma carnitine concentrations are lowered, such as by treatment with pivalate, carnitine can be mobilised from the muscle in order to normalise plasma carnitine concentrations ${ }^{26}$. Therefore, we expected that a reduced plasma carnitine concentration may lead to a reduction of the carnitine concentration in muscle. The finding that the concentration of carnitine was reduced in gastrocnemius and heart muscle of rats treated with oxidised fat indeed suggests that carnitine might have been mobilised from muscle. In rats treated with clofibrate, a reduction of muscle carnitine concentration has also been found ${ }^{20}$. A reduced carnitine concentration in muscle could also be due to a reduced uptake of carnitine due to a decreased activity of OCTN, which, however, is unlikely with respect to the finding that OCTN in liver were up regulated in rats fed the oxidised fat. As muscle also has a high expression of PPAR $\alpha$, we expect that the expression of OCTN in muscle was increased rather than reduced by the dietary oxidised fat.

The present study further shows that a dietary oxidised fat leads to an up regulation of OCTN2 in the small intestine. As PPAR $\alpha$ target genes (acyl-CoA oxidase, CYP4A1, CPT1a, CPT2) in the intestine were also up regulated in rats fed the oxidised fat, we assume that the increased expression of OCTN in intestine was also caused by activation of PPAR $\alpha$. As intestinal OCTN localised in the apical membrane of mucosa cells are able to transport carnitine from the diet into the cell ${ }^{27,28}$, an increased expression of these transporters may enhance their capacity to absorb carnitine. However, as $\mathrm{ATB}^{0+}$, another transporter involved in the intestinal absorption of carnitine ${ }^{27}$, was down regulated in rats fed the oxidised fat, it is difficult to draw conclusions about the whole intestinal absorption of carnitine from the diet. Nevertheless, the observed up regulation of intestinal OCTN may be relevant because they are polyspecific and do not only transport carnitine from the intestinal lumen into the mucosa cell but are also able to bind various drugs such as verapamil, spironolactone or mildronate and other monovalent cations ${ }^{14,28,55-58}$. As oxidised fats increase the gene expression of OCTN in the small intestine, it is possible that these fats also increase the absorption of various drugs from the intestine.

The hypothesis that the up regulation of OCTN was caused by PPAR $\alpha$ activation provides also an explanation for the observed increased hepatic carnitine concentrations in fasted rats $^{16,17}$. During fasting, NEFA are liberated from adipose tissue and act as activators of PPAR $\alpha$ when they have entered the liver. Activation of PPAR $\alpha$ up regulates many genes involved in hepatic mitochondrial and peroxisomal $\beta$-oxidation of fatty acids to supply acetyl-CoA used for the generation of ATP via the citrate cycle and for the generation of ketone bodies, an important fuel for the brain during fasting ${ }^{59,60}$. These metabolic adaptations during fasting triggered by PPAR $\alpha$ aim to minimise the use of protein and carbohydrates as fuel and allow mammals to survive long periods of energy deprivation. CPT are rate limiting for $\beta$-oxidation of fatty acids ${ }^{61,62}$. The up regulation of CPT, which is essential for the metabolic adaptations occurring during fasting, might increase the demand for carnitine in liver cells. We postulate that up regulation of OCTN by PPAR $\alpha$ activation is a means to supply liver cells with sufficient carnitine required for the transport of excessive amounts of fatty acids into the mitochondrion, and therefore plays an important role in the adaptive response of liver metabolism to fasting.

In conclusion, the present study shows that an oxidised fat causes an up regulation of OCTN2 in the liver and small intestine of rats. As OCTN2 catalyses the uptake of carnitine into cells, these fats influence whole-body carnitine homeostasis. An increased hepatic carnitine concentration in rats treated with oxidised fat may be at least in part due to an increased uptake of carnitine from blood into the liver. Since OCTN2 binds not only carnitine but also various drugs, the possibility exists that increased OCTN2 expression in the small intestine may improve the absorption of various drugs.

\section{References}

1. McGarry JD \& Brown NF (1997) The mitochondrial carnitine palmitoyltransferase system. From concept to molecular analysis. Eur J Biochem 244, 1-14.

2. Brass EP (2002) Pivalate-generating prodrugs and carnitine homeostasis in man. Pharmacol Rev 54, 589-598.

3. Steiber A, Kerner J \& Hoppel CL (2004) Carnitine: a nutritional, biosynthetic, and functional perspective. Mol Asp Med 25, 455-473.

4. Rebouche CJ \& Seim H (1998) Carnitine metabolism and its regulation in microorganisms and mammals. Annu Rev Nutr 18, 39-61.

5. Hoppel CL \& Davis AT (1986) Inter-tissue relationships in the synthesis and distribution of carnitine. Biochem Soc Trans 14, 673-674.

6. Vaz FM \& Wanders RJ (2002) Carnitine biosynthesis in mammals. Biochem J 361, 417-429.

7. Lahjouji K, Mitchell GA \& Qureshi IA (2001) Carnitine transport by organic cation transporters and systemic carnitine deficiency. Mol Genet Metab 73, 287-297.

8. Tein I (2003) Carnitine transport: pathophysiology and metabolism of known defects. J Inherit Metab Dis 26, 147-169.

9. Tamai I, Yabuuchi H, Nezu J, Sai Y, Oku A, Shimane M \& Tsuji A (1997) Cloning and characterization of a novel human $\mathrm{pH}$-dependent organic cation transporter, OCTN1. FEBS Lett 419, 107-111.

10. Tamai I, Ohashi R, Nezu J, Yabuuchi H, Oku A, Shimane M, Sai Y \& Tsuji A (1998) Molecular and functional identification of sodium ion-dependent, high affinity human carnitine transporter OCTN2. J Biol Chem 273, 20378-20382.

11. Tamai I, Ohashi R, Nezu JI, Sai Y, Kobayashi D, Oku A, Shimane M \& Tsuji A (2000) Molecular and functional characterization of organic cation/carnitine transporter family in mice. J Biol Chem 275, 40064-40072.

12. Ohashi R, Tamai I, Yabuuchi H, Nezu JI, Oku A, Sai Y, Shimane M \& Tsuji A (1999) $\mathrm{Na}^{+}$-dependent carnitine transport by organic cation transporter (OCTN2): its pharmacological and toxicological relevance. J Pharmacol Exp Ther 291, 778-784.

13. Ohashi R, Tamai I, Nezu Ji J, Nikaido H, Hashimoto N, Oku A, Sai Y, Shimane M \& Tsuji A (2001) Molecular and physiological evidence for multifunctionality of carnitine/organic cation transporter OCTN2. Mol Pharmacol 59, 358-366. 
14. Wu X, Huang W, Prasad PD, Seth P, Rajan DP, Leibach FH, Chen J, Conway SJ \& Ganapathy V (1999) Functional characteristics and tissue distribution pattern of organic cation transporter 2 (OCTN2), an organic cation/carnitine transporter. $J$ Pharmacol Exp Ther 290, 1482-1492.

15. Slitt AL, Cherrington NJ, Hartley DP, Leazer MT \& Klaassen CD (2002) Tissue distribution and renal developmental changes in rat organic cation transporter mRNA levels. Drug Metab Dispos 30, 212-219.

16. McGarry JD, Robles-Valdes C \& Foster DW (1975) Role of carnitine in hepatic ketogenesis. Proc Natl Acad Sci USA 72, 4385-4388.

17. Brass EP \& Hoppel CL (1978) Carnitine metabolism in the fasting rat. J Biol Chem 253, 2688-2693.

18. Paul HS \& Adibi SA (1979) Paradoxical effects of clofibrate on liver and muscle metabolism in rats. Induction of myotonia and alteration of fatty acid and glucose oxidation. J Clin Invest $\mathbf{6 4}$, 405-412.

19. Schoonjans K, Peinado-Onsurbe J, Lefebvre AM, Heyman RA, Briggs M, Deeb S, Staels B \& Auwerx J (1996) PPAR $\alpha$ and PPAR $\gamma$ activators direct a distinct tissue-specific transcriptional response via a PPRE in the lipoprotein lipase gene. Embo $J \mathbf{1 5}$, 5336-5348.

20. Luci S, Geissler S, König B, Koch A, Stangl GI, Hirche F \& Eder K (2006) PPAR $\alpha$ agonists up-regulate organic cation transporters in rat liver cells. Biochem Biophys Res Commun 24, 704-708.

21. Chao P-M, Chao C-Y, Lin F-J \& Huang C-J (2001) Oxidized frying oil up-regulates hepatic acyl-CoA oxidase and cytochrome P450 4A1 genes in rats and activates PPAR $\alpha$. J Nutr 131, 3166-3174.

22. Chao P-M, Hsu SC, Lin F-J, Li YJ \& Huang C-J (2004) The up-regulation of hepatic acyl-CoA oxidase and cytochrome P450 4A1 mRNA expression by dietary oxidized frying oil is comparable between male and female rats. Lipids 39, 233-238.

23. Chao PM, Yang MF, Tseng YN, Chang KM, Lu KS \& Huang CJ (2005) Peroxisome proliferation in liver of rats fed oxidized frying oil. J Nutr Sci Vitaminol (Tokyo) 51, 361-368.

24. Sülzle A, Hirche F \& Eder K (2004) Thermally oxidized dietary fat upregulates the expression of target genes of PPAR $\alpha$ in rat liver. J Nutr 134, 1375-1383.

25. Luci S, König B, Giemsa B, Huber S, Hause G, Kluge H, Stangl GI \& Eder K (2007) Feeding of a deep-fried fat causes PPAR $\alpha$ activation in the liver of pigs as a non-proliferating species. $\mathrm{Br} J$ Nutr 97, 872-882.

26. Nakajima H, Kodo N, Inoue F, Kizaki Z, Nukina S, Kinugasa A \& Sawada T (1996) Pivalate affects carnitine status but causes no severe metabolic changes in rat liver. J Nutr 126, 1683-1687.

27. Taylor PM (2001) Absorbing competition for carnitine. $J$ Physiol 532, 283.

28. Kato Y, Sugiura M, Sugiura T, Wakayama T, Kubo Y, Kobayashi D, Sai Y, Tamai I, Iseki S \& Tsuji A (2006) Organic cation/ carnitine transporter OCTN2 (Slc22a5) is responsible for carnitine transport across apical membranes of small intestinal epithelial cells in mouse. Mol Pharmacol 70, 829-837.

29. Nakanishi T, Hatanaka T, Huang W, Prasad PD, Leibach FH, Ganapathy ME \& Ganapathy V (2001) $\mathrm{Na}^{+}$- and $\mathrm{Cl}^{-}$-coupled active transport of carnitine by the amino acid transporter $\mathrm{ATB}^{0+}$ from mouse colon expressed in HRPE cells and Xenopus oocytes. $J$ Physiol 532, 297-304.

30. Deutsche Gesellschaft für Fettwissenschaften (1994) Einheitsmethoden zur Untersuchung von Fetten, Fettprodukten, Tensiden und verwandten Stoffen. Stuttgart, Germany: Wissenschaftliche Verlagsgesellschaft.

31. Sidwell CG, Salwin H, Benca M \& Mitchell JH Jr (1954) The use of thiobarbituric acid as a measure of fat oxidation. $J \mathrm{Am}$ Oil Chem Soc 31, 603-606.
32. Recknagel RO \& Glende EA Jr (1984) Spectrophotometric detection of lipid conjugated dienes. Methods Enzymol 105, 331-337.

33. International Union of Pure and Applied Chemistry (2000) Determination of polar compounds, polymerized and oxidized triacylglycerols, and diacylglycerols in oils and fats. Pure Appl Chem 72, 1563-1575.

34. Endo Y, Li CM, Tagiri-Endo M \& Fujimoto K (2001) A modified method for the estimation of total carbonyl compounds in heated and frying oils using 2 propanol as a solvent. $J$ Am Oil Chem Soc 78, 1021-1024.

35. McGarry JD \& Foster DW (1976) An improved and simplified radioisotopic assay for the determination of free and esterified carnitine. J Lipid Res 17, 277-281.

36. Parvin R \& Pande SV (1977) Microdetermination of (-)carnitine and carnitine acetyltransferase activity. Anal Biochem 79, 190-201.

37. Christiansen RZ \& Bremer J (1978) Acetylation of tris(hydroxymethyl)aminomethane (Tris) and Tris derivatives by carnitine acetyltransferase. FEBS Lett 86, 99-102.

38. König B \& Eder K (2006) Differential action of 13-HPODE on PPAR $\alpha$ downstream genes in rat Fao and human HepG2 hepatoma cell lines. J Nutr Biochem 17, 410-418.

39. Pfaffl MW (2001) A new mathematical model for relative quantification in real-time RT-PCR. Nucleic Acids Res 29, e45.

40. Delerive P, Furman C, Teissier E, Fruchart JC, Duriez P \& Staels B (2000) Oxidized phospholipids activate PPAR $\alpha$ in a phospholipase A2-dependent manner. FEBS Lett 471, 34-38.

41. Mishra A, Chaudhary A \& Sethi S (2004) Oxidized $\omega-3$ fatty acids inhibit NF- $\kappa \mathrm{B}$ activation via a PPAR $\alpha$-dependent pathway. Arterioscl Thromb Vasc Biol 24, 1621-1627.

42. Yoshida H \& Kajimoto G (1989) Effect of dietary vitamin E on the toxicity of autoxidized oil to rats. Ann Nutr Metab 33, $153-161$

43. Liu J-F \& Huang C-J (1996) Dietary oxidized frying oil enhances tissue $\alpha$-tocopherol depletion and radioisotope tracer excretion in vitamin E-deficient rats. J Nutr 126, 2227-2235.

44. National Research Council (1995) Nutrient Requirements of Laboratory Animals, 4th revised version. Washington, DC: National Academy Press.

45. Mandard S, Müller M \& Kersten S (2004) Peroxisome proliferator receptor $\alpha$ target genes. Cell Mol Life Sci 61, 393-416.

46. Corcos Benedetti P, D’Aquino M, Di Felice M, Gentili V, Tahliamonte B \& Tomassi G (1987) Effects of a fraction of thermally oxidized soy bean oil on growing rats. Nutr Rep Int 36, 387-401.

47. Hayam I, Cogan U \& Mokady S (1993) Dietary oxidized oil enhances the activity of $\left(\mathrm{Na}^{+}, \mathrm{K}^{+}\right)$ATPase and acetylcholinesterase and lowers fluidity of rat erythrocyte membrane. J Nutr Biochem 4, 563-569.

48. Hayam I, Cogan U \& Mokady S (1995) Dietary oxidized oil and the activity of antioxidant enzymes and lipoprotein peroxidation in rats. Nutr Res 15, 1037-1044.

49. Hochgraf E, Mokady S \& Cogan U (1997) Dietary oxidized linoleic acid modifies lipid composition of rat liver microsomes and increases their fluidity. $J$ Nutr 127, 681-686.

50. Borsting CF, Engberg RM, Jakobsen K, Jensen SK \& Anderson JO (1994) Inclusion of oxidized fish oil in mink diets. 1. Influence on nutrient digestibility and fatty-acid accumulation in tissues. J Anim Physiol Anim Nutr 72, 132-145.

51. Yokogawa K, Miya K, Tamai I, Higashi Y, Nomura M, Miyamoto K \& Tsuji A (1999) Characteristics of L-carnitine transport in cultured human hepatoma HLF cells. J Pharm Pharmacol 51, 935-940.

52. Yabuuchi H, Tamai I, Nezu J, Sakamoto K, Oku A, Shimane M, Sai Y \& Tsuji A (1999) Novel membrane transporter OCTN1 
mediates multispecific, bidirectional, and $\mathrm{pH}$-dependent transport of organic cations. J Pharmacol Exp Ther 289, 768-773.

53. Evans AM \& Fornasini G (2003) Pharmacokinetics of L-carnitine. Clin Pharmacokinet 42, 941-967.

54. Tamai I, China K, Sai Y, Kobayashi D, Nezu J, Kawahara E \& Tsuji A (2001) $\mathrm{Na}^{+}$-coupled transport of L-carnitine via highaffinity carnitine transporter OCTN2 and its subcellular localization in kidney. Biochim Biophys Acta 1512, 273-284.

55. Koepsell H \& Endou H (2004) The SLC22 drug transporter family. Pflugers Arch 447, 666-676.

56. Lahjouji K, Elimrani I, Lafond J, Leduc L, Qureshi IA \& Mitchell GA (2004) L-Carnitine transport in human placental brush-border membranes is mediated by the sodium-dependent organic cation transporter OCTN2. Am J Physiol Cell Physiol 287, C263-C269.

57. Grube M, Meyer zu Schwabedissen HE, Prager D, et al. (2006) Uptake of cardiovascular drugs into the human heart: expression, regulation, and function of the carnitine transporter OCTN2 (SLC22A5). Circulation 113, 1114-1122.

58. Hirano T, Yasuda S, Osaka Y, Kobayashi M, Itagaki S \& Iseki $\mathrm{K}$ (2006) Mechanism of the inhibitory effect of zwitterionic drugs (levofloxacin and grepafloxacin) on carnitine transporter (OCTN2) in Caco-2 cells. Biochim Biophys Acta 1758, $1743-1750$.

59. Kersten S, Seydoux J, Peters JM, Gonzalez FJ, Desvergne B \& Wahli W (1999) Peroxisome proliferator-activated receptor $\alpha$ mediates the adaptive response to fasting. $J$ Clin Invest 103, 1489-1498.

60. Cheon Y, Nara TY, Band MR, Beever JE, Wallig MA \& Nakamura MT (2005) Induction of overlapping genes by fasting and a peroxisome proliferator in pigs: evidence of functional PPAR $\alpha$ in nonproliferating species. Am J Physiol Integr Comp Physiol 288, R1525-R1535.

61. Brandt JM, Djouadi F \& Kelly D (1998) Fatty acids activate transcription of the muscle carnitine palmitoyltransferase I gene in cardiac myocytes via the peroxisome proliferator-activated receptor $\alpha$. J Biol Chem 273, 23786-23792.

62. Mascaro C, Acosta E, Ortiz JA, Marrero PF, Hegardt FG \& Haro D (1998) Control of human muscle-type carnitine palmitoyltransferase I gene transcription by peroxisome proliferator-activated receptor. J Biol Chem 273, $8560-8563$. 